\title{
Analisis Pengaruh Sektor Pengangkutan dan Komunikasi terhadap Pertumbuhan Ekonomi Kota Banyuwangi Tahun 2010-2014 (PDRB)
}

\author{
Analysis of Transportation and Communications Sector Effect to Economic \\ Growth of Banyuwangi City in 2010-2014 GRDP
}

\author{
Wahyudi Setiawan, Rafael Purtomo S ${ }^{1}$, Andjar Widjajanti \\ Jurusan Ilmu Ekonomi dan Studi Pembangunan, Fakultas Ekonomi dan Bisnis, Universitas Jember \\ Jalan Kalimantan 37, Jember 68121 \\ *e-mail: rafaelpurtomosomaji@yahoo.co.id
}

\begin{abstract}
Abstrak
Sektor pengangkutan dan komunikasi mempunyai keterkaitan langsung dan tidak langsung terhadap industri hulu dan terhadap output di Kabupaten Banyuwangi. Tujuan penelitian ini adalah mengetahui pengaruh perkembangan sektor transportasi dan komunikasi terhadap pertumbuhan ekonomi, serta mengadakan peramalan perkembangan pertumbuhan ekonomi di Kota Banyuwangi. Jenis penelitian ini adalah penelitian non-survey dengan metode eksplanatory, yaitu penelitian untuk mencari besar, ada tidaknya dan bagaimana pola hubungan antara dua variabel atau lebih. Unit penelitian yang digunakan adalah kinerja sektor pengangkutan dan komunikasi terhadap Produk Domestik Regional Bruto (PDRB) dan pertumbuhan ekonomi wilayah Kota Banyuwangi pada tahun 2010-2014. Analisis menggunakan regresi linier sederhana dan analisis trend. Hasil analisis data menunjukkan bahwa perkembangan sektor transportasi dan komunikasi terhadap pertumbuhan ekonomi di Kota Banyuwangi menunjukkan trend perkembangan yang positif pada tahun 2010-2014 dengan kecenderungan yang meningkat dari tahun ke tahun. Kinerja sektor transportasi dan komunikasi berpengaruh nyata terhadap pertumbuhan ekonomi di Kota Banyuwangi (signifikansi sebesar 0,000). Peramalan terhadap kinerja sektor transportasi dan komunikasi, perkembangan Produk Domestik Regional Bruto (PDRB) dan pertumbuhan ekonomi Kabupaten Banyuwangi pada tahun 2015 menunjukkan hasil yang meningkat, yaitu dengan nilai kinerja sektor transportasi dan komunikasi sebesar 654.689,34 juta rupiah, Produk Domestik Regional Bruto (PDRB) sebesar 15.095.868,203 dan pertumbuhan ekonomi sebesar 5,92\%.
\end{abstract}

Kata kunci: Sektor transportasi dan komunikasi, Produk Domestik Regional Bruto (PDRB)

\begin{abstract}
Transport and communications sector is have a the direct and un-directly linkage behind the upstream industry and also gives the best impact on output generated by Banyuwangi. The purpose of this study was to determine the effect of the development of the transport and communications sector to economic growth in the city of Banyuwangi and conduct forecasting the development of economic growth in the city of Banyuwangi if the review of the transport and communications sector. This research is a non-survey study with explanatory method, namely the search for large, there is not and how the pattern of relationships between two or more variables. Unit research used in this study is the performance of the transport and communications sector to the Gross Regional Domestic Product (GRDP) and economic growth of the city of Banyuwangi in 2010-2014. These analysis are simple linear regression and trend analysis with regression approach. The result showed that the development of the transport and communications sector to economic growth in the city of Banyuwangi showed a positive development trend in 2010-2014 with an upward trend from year to year. Transport and communications sector performance significantly affect economic growth in the city of Banyuwangi with a value of 37.964 t-test and significance value of 0.000. Forecasting the performance of the transport and communications sector, the development of Gross Regional Domestic Product (GRDP) and economic growth Banyuwangi in 2015 showed improved results compared to previous years, with the value of the transport and communications sector performance amounted to 654,689.34 million, Gross Regional Domestic Product (GRDP) of 15,095,868.203 million and an economic growth of 5.92\%.
\end{abstract}

Keywords: Transport and Communication Sector, Gross Regional Domestic Product (GRDP)

\section{Coresponding author}

e-Journal Ekonomi Bisnis dan Akutansi, 2017, Volume IV (1) : 67-71 


\section{Pendahuluan}

Pertumbuhan ekonomi suatu wilayah merupakan suatu proses kenaikan output perkapita dalam jangka panjang. Hal yang beraneka ragam tersebut ditekankan pada tiga aspek, yaitu: proses, output perkapita, dan kesinambungan. Sebagai suatu proses, pembangunan ekonomi dapat diartikan sebagai transisi dari suatu tingkat ekonomi yang bercorak sederhana menuju tingkat ekonomi yang lebih maju mencakup kegiatan yang beraneka ragam. Dalam transisi tersebut, terlaksananya suatu transformasi yang berarti perubahan pada pertimbangan-pertimbangan keadaan yang berkisar pada landasan kegiatan ekonomi dan melekat pada tata susunan ekonomi dan melekat pada tata susunan dalam kehidupan bermasyarakat (Djojohadikusumo, 1994:90). Sedangkan menurut Rostow (dalam Arsyad, 2004:47), proses-proses pembangunan ekonomi bisa dibedakan ke dalam lima tahap, yaitu masyarakat tradisional (the traditional society), prasarat tinggal landas (the preconditions for take off), tinggal landas (take off), menuju kedewasaan (the drive to maturity) dan masa konsumsi tinggi (the high mass consumption).

Sesuai dengan kebijakan otonomi daerah yang memberikan kewenangan untuk mengatur dan mengurus kepentingan masyarakat setempat menurut prakarsa sendiri berdasarkan aspirasi masyarakat sesuai dengan peraturan perundang-undangan (Undang-Undang Nomor 22 Tahun 1999), pemerintah daerah berhak untuk menggali potensi perekonomian di wilayahnya untuk mewujudkan pertumbuhan perekonomian yang menekankan pada tiga aspek (proses, output perkapita, dan jangka panjang). Berdasarkan kewenangan tersebut pemerintah daerah berhak untuk mengolah potensipotensi perekonomian yang ada wilayahnya, termasuk juga pada sektor transportasi dan komunikasi. Sektor transportasi dan komunikasi merupakan salah satu sektor yang memberikan sumber terhadap Produk Domestik Regional Bruto (PDRB) suatu kabupaten atau kota seiring dengan kemajuan tingkat perekonomian dari kabupaten atau kota tersebut.

Kabupaten Banyuwangi merupakan salah satu kabupaten di Propinsi Jawa Timur yang merupakan pintu gerbang untuk menuju Propinsi Bali, sehingga dengan demikian sektor transportasi dan komunikasi menjadi sangat berperan dalam pengembangan perekonomian daerah. Dari sudut ekonomi makro, fungsi transportasi adalah untuk menunjung pembangunan dan membantu tercapainya alokasi sumber-sumber ekonomi secara optimal dan merata. Jasa transportasi harus dapat tersedia secara cukup, murah, dan merata agar semua kegiatan pembangunan dapat berjalan dengan lancar, sesuai dengan harapan yaitu mampu meningkatkan kesejahteraan masyarakat. Transportasi yang baik akan menjamin tersedianya faktor-faktor produksi dan barang konsumsi akhir melalui meningkatnya kelancaran arus barang dalam perekonomian. Selain itu transportasi juga diperlukan dalam memperluas pasar, dimana dengan adanya alat-alat transportasi dapat mencapai wilayahwilayah pemasaran yang jauh. Adanya hubungan yang erat antara tingkat perkembangan perekonomian suatu negara dengan kondisi transportasinya dapat dilihat dari tinggi rendahnya faktor mobilitas di negara tersebut. Dengan semakin baik sistem transportasi maka akan bertambah pula mobilitas unsur-unsur perekonomian dan akan bertambah tinggi pula produktivitas yang dapat dicapai oleh sektor-sektor ekonomi yang ada.

Keperluan akan jasa transportasi mengikuti arah dan tingkat perkembangan kegiatan ekonomi yang akan memanfaatkannya, sebaliknya perkembangan ekonomi dipengaruhi oleh keadaan sistem transportasi yang melayaninya. Oleh karena itu permintaan terhadap produk industri transportasi merupakan permintaan turunan (derived demand), karena keperluan jasa transportasi mengikuti perkembangan kegiatan produksi dan ekonomi yang akan memanfaatkannya. Jika kegiatan produksi dan ekonomi meningkat, maka permintaan akan jasa transportasi bertambah dan jika terjadi kelesuan ekonomi keperluan akan jasa transportasi berkurang pula. Dengan kata lain permintaan terhadap jasa transportasi tergantung pada naik turunnya kegiatan ekonomi yang memerlukan layanan jasa transportasi tersebut (Kamaluddin, 2003).

Tujuan penelitian ini adalah mengetahui pengaruh perkembangan sektor transportasi dan komunikasi terhadap pertumbuhan ekonomi di Kota Banyuwangi serta mengadakan peramalan perkembangan pertumbuhan ekonomi di Kota Banyuwangi jika ditinjau dari sektor transportasi dan komunikasi.

\section{Metode}

Analisis yang digunakan untuk mengetahui pengaruh perkembangan sektor pengangkutan dan komunikasi terhadap pertumbuhan ekonomi wilayah Kota Banyuwangi menggunakan regresi linier sederhana. Sedangkan untuk meramalkan pertumbuhan ekonomi Kota Banyuwangi ditinjau dari sektor pengangkutan dan komunikasi menggunakan analisis trend perkembangan dengan menggunakan regresi.

\section{Jenis dan Sumber Data}

Jenis penelitian ini adalah penelitian non-survey dengan metode eksplanatory, yaitu penelitian untuk mencari besar, ada tidaknya dan bagaimana pola hubungan antara dua variabel atau lebih. Unit penelitian yang digunakan dalam penelitian ini adalah kinerja sektor pengangkutan dan komunikasi terhadap Produk Domestik Regional Bruto (PDRB) dan pertumbuhan ekonomi wilayah Kota Banyuwangi pada tahun 2010-2014. Data yang digunakan dalam penelitian ini adalah data sekunder selama periode waktu 2010-2014 yang diperoleh dari Badan Pusat Statistik (BPS) Kota Banyuwangi. Berbagai data yang akan dijadikan analisis, yaitu data-data sektor pengangkutan dan komunikasi, data Produk Domestik 
Regional Bruto (PDRB) kota Banyuwangi, serta data laju pertumbuhan ekonomi Kota Banyuwangi.

\section{Populasi dan Sampel}

Secara teoritis populasi yang digunakan dalam penelitian ini adalah aktivitas sektor pengangkutan dan komunikasi di Kota Banyuwangi. Adapun sampel yang digunakan dalam penelitian ini adalah kinerja sektor pengangkutan dan komunikasi di Kota Banyuwangi pada periode 2010 sampai dengan 2014, dengan pertimbangan data tersebut merupakan data sepuluh tahunan yang memungkinkan terjadinya perubahan-perubahan dalam perkembangan suatu kota.

\section{Hasil dan Pembahasan}

Gambaran umum perekonomian Kabupaten Banyuwangi diketahui dengan neraca perekonomian daerah, sedangkan untuk mengetahui indikator besaran produksi barang dan jasa salah satunya diketahui dengan menggunakan Produk Domestik Regional Bruto (PDRB). Nilai Produk Domestik Regional Bruto (PDRB) dan pertumbuhan ekonomi Kabupaten Banyuwangi tahun 2010-2014 menurut lapangan usaha atas dasar harga konstan tahun 2000 disajikan pada Tabel 1.

Tabel 1. Produk Domestik Regional Bruto (PDRB) dan pertumbuhan ekonomi Kabupaten Banyuwangi tahun 2010-2014 menurut lapangan usaha atas dasar harga konstan tahun 2000

\begin{tabular}{llc}
\hline Tahun & $\begin{array}{l}\text { PDRB } \\
\text { (juta rupiah) }\end{array}$ & $\begin{array}{l}\text { Pertumbuhan } \\
\text { ekonomi (\%) }\end{array}$ \\
\hline 2010 & $11.015 .195,24$ & \\
2011 & $11.794 .189,99$ & 7,07 \\
2012 & $12.655 .586,32$ & 7,30 \\
2013 & $13.511 .707,87$ & 6,76 \\
2014 & $14.251 .763,90$ & 5,48 \\
Rata-rata & $12.645 .688,66$ & 6,65 \\
\hline
\end{tabular}

Sumber: Badan Pusat Statistik Kab Banyuwangi, 2014.

Berdasarkan Tabel 1, menunjukkan bahwa Produk Domestik Regional Bruto (PDRB) Kabupaten Banyuwangi selalu mengalami kenaikan dari tahun ke tahun. Pada tahun 2010 bernilai sebesar Rp 11.015.195,24 juta meningkat menjadi Rp 11.794.189,99 juta pada tahun 2011. Tahun 2012 PDRB Kabupaten Banyuwangi kembali mengalami kenaikan menjadi sebesar Rp 12.655.586,32 juta. Kenaikan ini berlanjut pada tahun 2013 dan 2014, pada tahun 2013 sebesar Rp 13.511.707,87 dan Rp 14.251.763,90 pada tahun 2014 . Adapun tingkat pertumbuhan ekonomi Kabupaten Banyuwangi pada tahun 2010-2014 diilustrasikan pada Gambar 1.

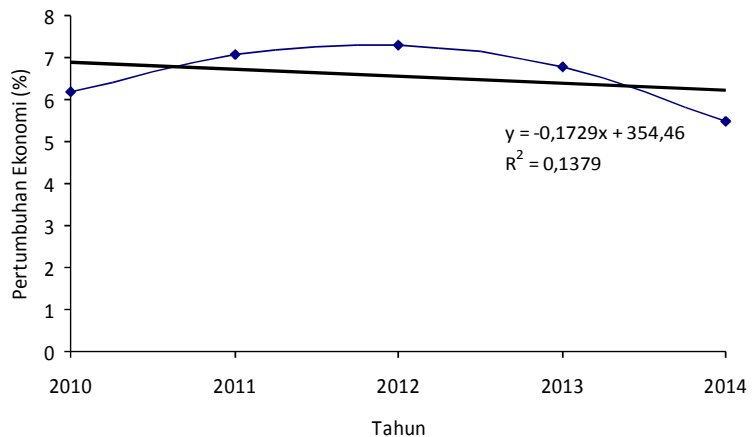

Gambar 1. Pertumbuhan Ekonomi Kabupaten Banyuwangi tahun 2010-2014

Berdasarkan Gambar 1, menunjukkan bahwa pertumbuhan ekonomi Kabupaten Banyuwangi cenderung menunjukkan trend yang menurun. Pertumbuhan ekonomi rata-rata Kabupaten Banyuwangi tahun 2010-2014 adalah sebesar 6,65\% dengan pertumbuhan tertinggi adalah tahun 2012 sebesar 7,30\% dan pertumbuhan terendah pada tahun 2014 sebesar $5,48 \%$. Hasil analisis trend menunjukkan bahwa dengan semakin bertambahnya tahun maka pertumbuhan ekonomi Kabupaten Banyuwangi akan menurun sebesar $0,1729 \%$.

Hasil pengujian pengaruh sektor transportasi dan komunikasi Kabupaten Banyuwangi terhadap kinerja pertumbuhan ekonomi wilayah Kabupaten Banyuwangi antara tahun 2010-2014 dengan menggunakan analisis regresi linier sederhana disajikan pada Tabel 2.

Tabel 2. Rekapitulasi Hasil Analisis Regresi Linier Sederhana

\begin{tabular}{lllll}
\hline $\begin{array}{l}\text { Variabel } \\
\text { Bebas }\end{array}$ & $\begin{array}{c}\text { Koefisien } \\
\text { regresi }\end{array}$ & $\begin{array}{c}\text { Penyajian } \\
\text { hipotesis }\end{array}$ & Sign. \\
& & t-hitung & t-tabel & \\
$\begin{array}{l}\text { Kinerja sektor } \\
\text { transportasi \& } \\
\text { komunikasi (X) }\end{array}$ & & & & \\
Konstanta & $-724,045$ & 37,964 & 3,182 & 0,000 \\
R & 0,998 & & & \\
F-hitung & 1441,263 & & & \\
F-tabel & 10,128 & & & \\
$(5 \% ; 5,44)$ & & & & \\
Signifikansi & 0,000 & & & \\
\hline
\end{tabular}

Berdasarkan analisis regresi linier sederhana yang ditampilkan pada Tabel 2, maka dapat dihasilkan persamaan regresi sebagai berikut :

$\mathrm{Y}=-724.045+24,164 \mathrm{X}$ 
Dari persamaan regresi linier berganda di atas dapat dilihat pengaruh dari variabel kinerja sektor transportasi dan komunikasi terhadap variabel PDRB Kabupaten Banyuwangi. Konstanta persamaan regresi $\left(b_{0}\right)$ sebesar 724.045, berarti bahwa jika variabel kinerja sektor transportasi dan komunikasi (X) sama dengan nol, maka PDRB Kabupaten Banyuwangi adalah sebesar minus 724.045 juta rupiah, sedangkan koefisien regresi (b) sebesar 24,164, berarti bahwa peningkatan kinerja sektor transportasi dan komunikasi sebesar Rp 1.000.000,-, maka akan terjadi peningkatan PDRB Kabupaten Banyuwangi sebesar Rp 24.300.000,--

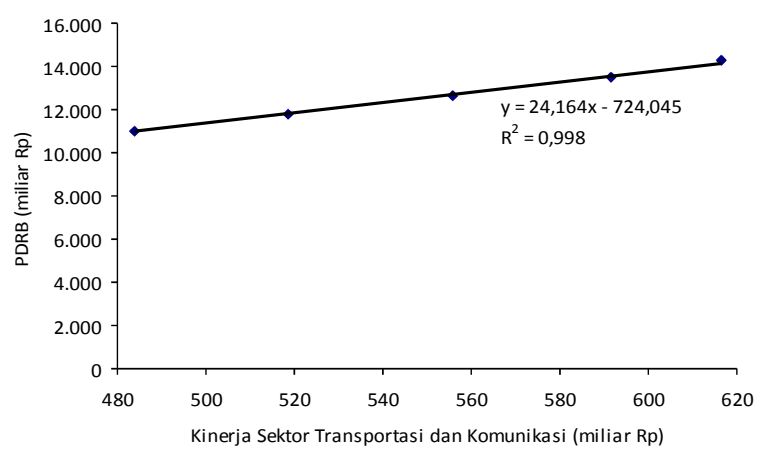

Gambar 2. Pengaruh kinerja sektor transportasi dan komunikasi terhadap PDRB Kabupaten Banyuwangi tahun 2010-2014

Hasil uji regresi linier sederhana (Tabel 2), diperoleh nilai t-hitung sebesar 37,964 dengan nilai signifikansi sebesar 0,000. Adapun nilai t-tabel berdasarkan taraf kesalahan 5\% dengan derajat bebas 3 adalah sebesar 3,182 . Berdasarkan hal di atas diketahui nilai t-hitung $>$ t-tabel $(37,964>3,182)$. Hal ini menunjukkan bahwa variabel kinerja sektor transportasi dan komunikasi mempunyai pengaruh yang signifikan terhadap PDRB Kabupaten Banyuwangi. Koefisien determinasi $\left(\mathrm{R}^{2}\right)$ sebesar 0,998, yang berarti bahwa variabel kinerja sektor transportasi dan komunikasi berpengaruh terhadap variabel dependen (PDRB Kabupaten Banyuwangi) sebesar 99,8\%, sedangkan sisanya yaitu sebesar $0,2 \%$ dipengaruhi oleh faktor lain di luar model.

Hasil konversi peramalan perkembangan pertumbuhan ekonomi di Kabupaten Banyuwangi ditinjau dari sektor transportasi dan komunikasi disajikan pada Tabel 3.

Berdasarkan data pada Tabel 3 dan dihitung dengan rumus regresi linier sederhana, maka diperoleh persamaan regresi sebagai berikut :

$\mathrm{Y}=553.285,309+33.801,343 \mathrm{X}$

Hasil peramalan nilai kinerja sektor transportasi dan komunikasi pada tahun 2015 yaitu sebesar 654.689,340 juta rupiah, sedangkan hasil peramalan nilai PDRB Kabupaten Banyuwangi pada tahun 2015 adalah sebesar $15.095 .868,20$ juta rupiah.
Tabel 3. Data Peramalan perkembangan partum-buhan ekonomi di Kabupaten Banyuwangi ditinjau dari sektor transportasi dan komunikasi

\begin{tabular}{lll}
\hline Tahun & $\begin{array}{l}\text { Nilai } \\
\text { Konversi }\end{array}$ & $\begin{array}{l}\text { Kinerja sektor transportasi } \\
\text { dan komunikasi (juta rupiah) }\end{array}$ \\
2010 & -2 & $483.920,14$ \\
2011 & -1 & $518.769,74$ \\
2012 & 0 & $555.670,22$ \\
2013 & 1 & $591.509,44$ \\
2014 & 2 & $616.557,01$ \\
\hline
\end{tabular}

Hasil peramalan ini menunjukkan bahwa terjadi peningkatan Produk Domestik Regional Bruto (PDRB) Kabupaten Banyuwangi sebesar 844.104,305 juta rupiah. Sedangkan jika ditinjau dari pertumbuhan ekonomi, Kabupaten Banyuwangi akan mengalami pertumbuhan ekonomi sebesar 5,92\% pada tahun 2015 .

Peran sektor transportasi dan komunikasi terhadap pertumbuhan ekonomi wilayah sangatlah penting, karena pertumbuhan ekonomi wilayah sebagian diperoleh dari PDRB sektor transportasi dan komunikasi yang memberikan peran yang sangat besar. Pertumbuhan sektor transportasi dan komunikasi pergerakannya dari tahun ke tahun cukup signifikan artinya keadaan sektor transportasi dan komunikasi seimbang pertahunnya, pergerakan pertumbuhan sektor transportasi dapat dilihat pada Gambar 3. Oleh karena itu Kabupaten Banyuwangi perlu sekali meningkatkan sektor transportasi dan komunikasi dengan sarana dan prasarana yang dibutuhkan masyarakat, agar dapat menarik masyarakat untuk menggunakannya target pendapatan yang berasal dari sektor transportasi dan komunikasi dapat tercapai.

Perkembangan kinerja sektor transportasi dan komunikasi terhadap pertumbuhan ekonomi wilayah Kabupaten Banyuwangi memberikan trend yang positif, berarti perkembangan kontribusi sektor transportasi dan komunikasi terhadap pertumbuhan ekonomi wilayah Kabupaten Banyuwangi mempunyai kecenderungan naik dari tahun ke tahun yang berarti pula peranan atau sumbangan sektor transportasi dan komunikasi terhadap pertumbuhan ekonomi wilayah Kabupaten Banyuwangi selalu meningkat pada tiap tahunnya. Hal ini disebabkan oleh peningkatan pembangunan sektor transportasi dan komunikasi yang berupa sarana fisik sehingga sektor transportasi dan komunikasi juga semakin meningkat yang disertai menurunnya sektor lain, sehingga kontribusi sektor yang bersangkutan terhadap 
pertumbuhan ekonomi wilayah juga menurun yang pada akhirnya meningkatkan kontribusi sektor transportasi dan komunikasi terhadap pertumbuhan ekonomi wilayah di Kabupaten Banyuwangi.

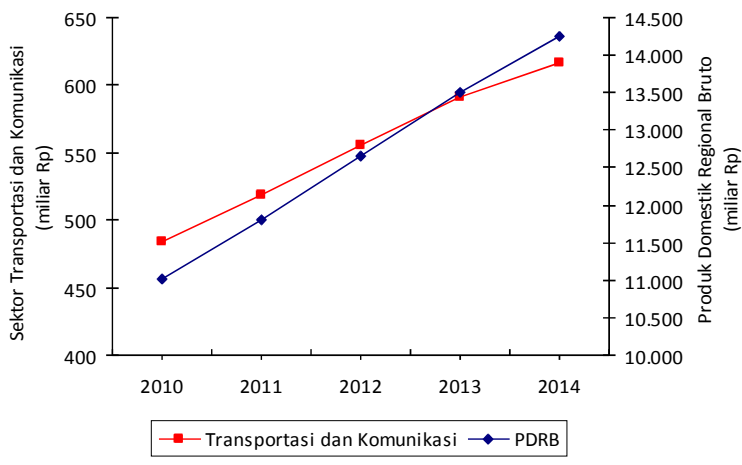

Gambar 3. Perkembangan kinerja sektor transportasi dan komunikasi serta PDRB Kabupaten Banyuwangi tahun 2010-2014

Menurut Webber (dalam Tarigan, 2004:141), bahwa lokasi setiap industri tergantung pada total biaya transportasi dan tenaga kerja dimana penjumlahan keduanya harus minus. Tempat yang mempunyai total biaya transportasi dan tenaga kerja yang minimum adalah identik dengan tingkat keuntungan yang maksimum. Hal ini berarti sektor transportasi dan komunikasi akan membawa dampak yang besar bagi sektor-sektor yang lain di Kabupaten Banyuwangi yaitu sektor perdagangan hotel dan pariwisata, sektor industri, serta sektor pertanian. Dengan meningkatnya sektor-sektor tersebut maka pertumbuhan ekonomi di Kabupaten Banyuwangi juga akan semakin meningkat.

\section{Simpulan}

Perkembangan sektor transportasi dan komunikasi terhadap pertumbuhan ekonomi di Kota Banyuwangi menunjukkan trend perkembangan yang positif pada tahun 2010-2014 dengan kecenderungan yang meningkat dari tahun ke tahun. Kinerja sektor transportasi dan komunikasi berpengaruh nyata terhadap pertumbuhan ekonomi di Kota Banyuwangi dengan nilai t-hitung sebesar 37,964 dan nilai signifikansi sebesar 0,000. Peramalan terhadap kinerja sektor transportasi dan komunikasi, perkembangan Produk Domestik Regional Bruto (PDRB) dan pertumbuhan ekonomi Kabupaten
Banyuwangi pada tahun 2015 menunjukkan hasil yang meningkat dibandingkan dengan tahun-tahun sebelumnya, yaitu dengan nilai kinerja sektor transportasi dan komunikasi sebesar 654.689,34 juta rupiah, Produk Domestik Regional Bruto (PDRB) sebesar 15.095.868,203 dan pertumbuhan ekonomi sebesar $5,92 \%$.

Fasilitas umum dalam sektor transportasi dan komunikasi hendaknya semakin diperbaiki supaya sektor transportasi dan komunikasi dapat lebih meningkat lagi sehingga mobilitas dan aksesbilitas masyarakat Banyuwangi semakin tinggi dan bisa diharapkan meningkatkan dan memperlancar pergerakan roda perekonomi Kabupaten Banyuwangi. Penggunaan alat transportasi umum yang semakin bergeser ke arah kendaraan pribadi dikarenakan biaya yang dikeluarkan untuk mobilitas semakin rendah. Pemerintah hendaknya melakukan kebijakan yang dapat membantu pengusaha angkutan umum agar tidak semakin merugi dan pada akhirnya gulung tikar. Kebijakan ini dapat berbentuk perbaikan fasilitas untuk angkutan umum agar masyarakat atau penumpang bisa merasa lebih nyaman.

\section{Keterbatasan Penelitian}

Keterbatasan dalam penelitian ini adalah data yang diperoleh peneliti hanya berjangka 5 tahun, seharusnya untuk data pertumbuhan dan perkembangan suatu wilayah atau daerah sebaiknya berjangka 10 tahun (Kamalludin;2003).

\section{Referensi}

Arsyad, Lincolin, 1999. Pengantar Perencanaan dan Pembangunan Ekonomi Daerah. Yogyakarta: BPFE.

Boediono, 1999. Teori Pertumbuhan Ekonomi. BPFE, Yogyakarta.

Djojohadikusumo, Sumitro., 1994. Perkembangan Pemikiran Ekonom Dasar Teori Ekonomi Pertumbuhan dan Ekonomi Pembangunan. Jakarta: PT. Pustaka LP3ES.

Indriantoro, dan Supomo, 2002. Metodologi Penelitian Bisnis untuk Akuntansi dan Manajemen, Edisi Pertama, Yogyakarta: BPFE.

Kamaludin, R., 2003. Ekonomi Transportasi Karakteristik Teori dan Kebijakan. Jakarta: Ghalia Indonesia.

Suhro, K., 2013. Kontribusi Sektor Pengangkutan dan Komunikasi terhadap Pertumbuhan Ekonomi Kabupaten Jember. Skripsi. Jember: Fakultas Ekonomi Universitas Jember.

Supranto, J., 1995. Metode Ramalan Kuantitatif untuk Perencanaan Ekonomi dan Bisnis. Jakarta: Rineka Cipta.

Tarigan, Robinson., 2007. Ekonomi Regional, Teori dan Aplikasi. Cetakan Keempat, Jakarta: PT Bumi Aksara. 